\title{
Parametric Control of the Diversification of Economic Growth by Stimulating Certain Industries
}

\author{
A.A. Ashimov \\ Kazakh National Research Technical University named \\ after K.I. Satpayev \\ Almaty, the Republic of Kazakhstan
}

\author{
Yu.V. Borovskiy \\ Kazakh National Research Technical University named \\ after K.I. Satpayev \\ Almaty, the Republic of Kazakhstan
}

\author{
M.A. Onalbekov \\ Kazakh National Research Technical University named after K.I. Satpayev \\ Almaty, the Republic of Kazakhstan
}

\begin{abstract}
The dynamic multi-country computable general equilibrium model was developed in the GAMS environment for the following regions: the Republic of Kazakhstan, the Russian Federation, the Republic of Belarus, the Republic of Armenia, the Kyrgyz Republic, the European Union (as one country), the USA, the People's Republic of China, the rest of the world (as one country), the Globe region by binding with the formed sets of social accounting matrices (SAM), and the recovered values of the elasticity of substitution coefficients of the corresponding production functions. The conditions for transferring the results of computational experiments on the basis of the model to the subject area were evaluated. The effectiveness of economic growth diversification was shown on the example of the Republic of Kazakhstan through stimulating certain economic sectors based on solving extreme problem of economic growth by the parametric control approach.
\end{abstract}

Keywords-parametric control theory; computable general equilibrium model; economic diversification; economic growth

\section{INTRODUCTION}

Search for ways of diversified economic growth is a topical issue of developing countries. One way is direct stimulating certain important industries. The paper [1], on the basis of a dynamic computable general equilibrium model, studied the possibility of economic growth by stimulating research and development industry through scenario analysis of the impact of increasing investment there in the case of the Czech Republic. In [2] in case of Sri Lanka it was explored stimulating the service industry via changing taxes on the production of services and import duties, as well as consequently effects on total economic growth on the base of two developed computable general equilibrium models. The papers [3-6] studied of the economic growth opportunities of national economies through the stimulation of certain sectors were considered without solving the appropriate extreme problems of economic growth and without taking into account the effects of foreign economic relations on economic growth.

In this paper, a global multi-country computable general equilibrium model was constructed for the Republic of Kazakhstan and its trading partner regions. It was calibrated on the basis of generated social accounting matrices (SAM) and given values of elasticity of substitution coefficients of production functions. Also the conditions for transferring the results of computational experiments obtained on model to the subject area were evaluated. The industries to stimulate were selected by the analysis of economic structure of the Republic of Kazakhstan. The effectiveness of solving the extreme problem of diversification of economic growth by stimulating selected industries with the approach of the parametric control theory was shown.

\section{Model DeSIGN AND CALIBRATION}

The model was designed on the base of the following steps.

1. Selection of the composition of agents for each region.

2. Making assumptions for the model design.

3. Construction of a content description of regions.

4. Construction of the model based on the content description of regions.

5. Loading the model into the GAMS environment [7].

6. Selection of the regions.

7. Formation of a consistent set of social accounting matrices of selected regions for each year within 2004-2021 based on GTAP (Global Trade Analysis Project) [8] and the proposed algorithms for creating SAM based on national account systems and IMF forecast data, as well as the formation of elasticity of substitution coefficients of production functions.

8. Loading the set of SAM and elasticity of substitution coefficients into the GAMS environment.

9. Binding and calibration of the model based on loaded data.

In accordance with the step 1, the following composition of agents was selected: producers, households, governments. Producers were represented by 16 sectors: 1) Mining (except oil and gas), 2) Production of crude oil and gas, 3) Metal manufacture and engineering, 4) Metallurgical industry, 5) Education, healthcare, public policy, 6) Power, gas and hot water production and transmission, 7) Food, beverages and tobacco production, 8) Professional, scientific and technical activities, 9) Other industries, 10) Other services, 11) Farming, forestry and fishing, 12) Construction, 13) Manufacture of textiles, clothing, leather and related products, 14) Financial 
services, 15) Chemical and petrochemical production, 16) Transport. The model, also, contains an agent Globe in the Globe region.

In the step 2, the following assumptions were accepted.

Producer agent in its activities every year:

- produces one type of product (from the condition of costs minimization);

- produces gross value added (based on the use of factors: labor and capital of households);

- exports part of the output (from the condition of profit maximization);

- imports intermediate and investment products from other regions;

- consumes intermediate and investment products;

- pays tax deductions to its government.

Each producer agent solves the following two pairs of nested optimization problems:

- the problem of minimizing the costs of the industry for the acquisition of intermediate products and the cost of the GVA of the industry for a given output;

- the problem of minimizing the costs of the industry for the acquisition of production factors for a given output of final products;

- the problem of maximizing the profit from sales within and beyond the region for a given output;

- the problem of maximizing the profit from exports to various regions for a given level of export.

Household agent in its activities every year:

- receives income from the supply of factors (labor and capital) based on the demand for factors from the producers of its region;

- consumes consumer products (according to the solution of the problem of maximizing its utility function with the appropriate budget constraint);

- makes savings in the form of investment products on the basis of its income and consumption;

- pays tax deductions to the government of its region.

Government of each region in its activities every year:

- determines effective tax rates and receives income in the form of net tax revenues (including revenues from customs duties);

- consumes final products (government spending);

- makes savings in the form of investment products on the basis of its income and spending;

Agents of producer, household and government sectors every year solve jointly the following optimization problems:

- defining the optimal share of imports in consumption of each type of products from the condition of minimum costs for domestic and imported components of these products;

- defining the optimal regional structure of each type of imported products from the condition of minimum costs for this type of imported products.

In accordance with step 3, a content description of the economy which contains descriptions of the statements of the above listed optimization problems with the corresponding first-order conditions, other equations describing agents' functions, balance ratios for prices and quantities (real indicators measured in seller's prices), internal balances on state accounts and external balances on trade accounts was constructed. The content description also contains a system of composite endogenous prices for all 16 types of products in each region, including the prices of the buyer and seller, the prices of the exporter and importer, etc. The calculated values of prices provide the fulfillment of annual balance ratios that ensure:

- equilibrium in the markets for factors (labor and capital);

- equilibrium in the markets for each type of product;

- two-side balance of payments for each pair of regions;

- equilibrium between savings (of households, governments) and investments in the industries of the regions.

In accordance with step 4, based on a content description of the regions, a dynamic model consisting of the first-order conditions of optimization problems; the descriptions of other rules of the agents' activity; balance ratios for prices and quantities; dynamic equations describing the coefficients of production functions and supply of factors; as well as auxiliary equations for finding aggregate values was derived for computing scenarios.

In step 5, the derived model was loaded into the GAMS environment.

In accordance with step 6, the world economy was approximated by the functioning and interaction of these regions: 1) the Republic of Kazakhstan, 2) the Russian Federation, 3) the Republic of Belarus, 4) the Republic of Armenia, 5) the Kyrgyz Republic, 6) the European Union (as one country), 7) the USA, 8) the People's Republic of China, 9) the rest of the world (as one country), 10) the Globe region. Here, the first five countries form the Eurasian Economic Union (EAEU). As in the Globe model type [9], the Globe region was included into regions as well. This region imports transport services and exports them to all regions when each type of goods was exported from each region to each other region.

In accordance with step 7, a set of social accounting matrices of all regions for each of the considered years 20042021 was created. They show how the product flows (in money terms) and financial flows are distributed between the producers, households, government, importers and exporters. The mentioned SAM sets for 2004, 2007 and 2011 were extracted using a special converter from the GTAP database, as this database doesn't have data for the remaining years of the considered historical period of 2004-2014. So an algorithm and software were developed for evaluating such sets of SAM for the years where these SAM are not available. In particular, a set of algorithms for restoring such SAM was developed and implemented on the basis of the known national input-output tables (IOT) [10] and international trade data between the regions [11]. This set of algorithms includes:

- an auxiliary algorithm for transforming the IOT with the purpose of its compliance with the accepted industry structure of model;

- an auxiliary algorithm aimed at eliminating disparities in the available international trade statistics;

- the main algorithm for calculating all the elements of the required SAM, using the above auxiliary algorithms and some relationships between the SAM elements of the previous year. 
To evaluate SAM sets for the years where there are no observable IOT (for example, in the forecast period), a special algorithm was developed. This algorithm enables to evaluate SAM elements based on such indicators of the regions as GDP, total investment, quantity of imported goods, quantity of imported services, quantity of exported goods, quantity of exported services, total government revenues, total government spending in each region of model, and a set of SAM for regions of the model for the previous period. This algorithm includes the RAS algorithm [12], designed to evaluate the matrix of intermediate consumption of products by sectors based on the corresponding matrix of the previous period and the new values of the sums of its rows and columns.

Therefore, for the years 2005, 2006, 2008-2010 and 20122014, the required SAM sets were calculated using first algorithm based on available statistical sources containing input-output tables, mutual trade indicators, using base relationships calculated using known SAM for recent year (2004, 2007 or 2011). Second algorithm was used for the forecast period (2015-2021), using which the SAM sets were calculated on the basis of the above-mentioned forecast indicators of the regions provided by the International Monetary Fund [13].

In addition to the obtained SAM sets, the base of the model's initial data includes the values of the elasticity of substitution coefficients of various factors in the production functions of the all industries; the elasticity of substitution coefficients of different product types of in the output functions of producers', households' utility functions and aggregation functions that describe the consumption of agents, as well as the corresponding initial values of the dynamic model equations. These coefficients were taken from the GTAP database for 2004, 2007 and 2011 and then they were extrapolated to the remaining years of the calculation period (2004-2021) except for the three specified years.

In accordance with step 8, the obtained data on the SAM tables and the substitution coefficients were loaded into the GAMS environment.

Within step 9, in the GAMS environment, the model was linked to the selected regions by calibrating on the basis of SAM and data on the substitution coefficients.

\section{Testing The Model For The Possibility Of Its PRACTICAL APPLICATION}

The calibrated model was tested by three methods, the first two of which were proposed by the authors during the development of the parametric control theory.

\section{A. Evaluation of the Stability of Smooth Mappings Defined by the Model}

To estimate the stability of smooth mappings defined by the above given model, an implementation of a set of numerical algorithms described in [14] was used.

Due to the fact that the computing time of the above proposed algorithms grows approximately as geometric progression with increasing dimension of the domain of the mapping defined by the model, to complete the calculations in a reasonable time, it was necessary to limit the number of input variables for mappings defined by the model. In the experiments, we considered baseline mappings of the form $F: D \rightarrow E(\operatorname{dim} D=5$ and $\operatorname{dim} E=9)$, where the mapping arguments of $F$ mapping were the values of the value-added tax rates of the five EAEU countries for 2015, and as the output variables of $F$ mapping were taken the GDP values of all nine regions for 2021. The boundaries of $D$ five-dimensional parallelepiped with the center at the point $p=\left(p_{1}, \ldots, p_{5}\right)$, corresponding to the baseline values of the indicated tax rates differ from the values of $p_{i}$ by $0,5 p_{i}$. The results of numerical experiments based on the first two indicated algorithms demonstrated the absence of singular points of $F$ mapping in $D$ domain and its injectivity, consequently, the stability of such immersions, both for the baseline and for a number of scenario calculations of the model, corresponding to the derived solutions of the parametric control problems.

\section{B. Evaluation of the Stability Indicators of Mappings Defined by the Model}

In the experiments with the model, as $F$ set was considered the parallelepiped with the center at the point $p$, corresponding to the baseline values of all tax rates of all regions for 2004, and as $\boldsymbol{E}_{\boldsymbol{t}}$ set of the endogenous variables - GDP, exports, imports of all Regions of the model for the fixed target year $\boldsymbol{t}$ (since 2004 to 2021).

As an example, Table 1 shows the calculated values of the stability indicators of model for the base point $\boldsymbol{p}$ and $\boldsymbol{\alpha}=0.01$ (in percent). TABLE I. THE VALUES OF STABILITY INDICATORS For THE BASELINE
COMPUTATION OF THE MODEL

\begin{tabular}{|c|c|c|c|}
\hline Year & $\beta_{f}(p, 0,01)$ & Year & $\beta_{f}(p, 0,01)$ \\
\hline 2004 & 0.4536 & 2013 & 0 \\
\hline 2005 & 0.0813 & 2014 & 0 \\
\hline 2006 & 0.0097 & 2015 & 0 \\
\hline 2007 & 0.0061 & 2016 & 0 \\
\hline 2008 & 0.0032 & 2017 & 0 \\
\hline 2009 & 0.0015 & 2018 & 0 \\
\hline 2010 & 0.0006 & 2019 & 0 \\
\hline 2011 & 0.0001 & 2020 & 0 \\
\hline 2012 & 0 & 2021 & 0 \\
\hline
\end{tabular}

All of the stability indicators estimates listed in Table 1 don't exceed 0.4536 , which characterizes the stability of the model in calculations up to 2021 as sufficiently high.

\section{A Series of Counterfactual and Forecast Scenarios.}

According to the well-known macroeconomic theory, reducing taxes levied on producers and consumers, as well as increasing the government's demand for consumer products, leads to an increase in the region's output and GDP. In the framework of testing the model, on its basis, counterfactual and forecast scenarios were computed to assess the implementation of this theoretical provision. In particular, a scenario with a $10 \%$ reduction in effective rates of value added taxes, taxes on producer's income and 10\% increase in government consumption in each country of the EAEU was 
implemented. The results of the calculation of this scenario demonstrated a change in the GVA of each industry in the respective country ranging from $-3.85 \%$ to $6.16 \%$ and an increase in the GDP of all regions ranging from $0.0279 \%$ in 2009 for the world economy to $0.7715 \%$ in 2012 for the EAEU in comparison with the observed data.

The above given results of the three testing methods of the model allow to make a conclusion about the successful testing of the investigated model for the possibility of its practical application.

\section{STATEMENT AND SOLUTION OF THE PROBlEM OF DIVERSIFICATION OF ECONOMIC GROWTH BY STIMULATING CERTAIN INDUSTRIES USING THE PARAMETRIC CONTROL APPROACH}

Taking into account the role of metal manufacture and engineering industry in renewing the fixed assets of the economic sectors and the role of the chemical and petrochemical production industry in the economy of the oilproducing country (the Republic of Kazakhstan), the abovementioned sectors were chosen to stimulate.

During the evaluation of optimal measures aimed at GDP growth and the output growth in the selected economic sectors of the Republic of Kazakhstan in the medium term (20152021), the following parametric control problem was formulated on the basis of the model.

The problem statement is following: for the economy of the Republic of Kazakhstan, to find on the basis of the model the values of control parameters $\boldsymbol{u}(\boldsymbol{t})$ (efficient rates of producers' income tax, sales tax and customs duties differentiated by product types and industries; volume of government spending), which ensures the maximum value of $\boldsymbol{K}$ criterion (3) under the constraints on control instruments of the form $\boldsymbol{u}(\boldsymbol{t}) \in \boldsymbol{U}(\boldsymbol{t})$ and the constraints (1)-(2) on several endogenous variables. Here $t=\mathbf{2 0 1 5}, \ldots, 2021 ; U(t)-$ parallelepiped with the center at the point of $\boldsymbol{u}(\boldsymbol{t})$ baseline values and with boundaries, differing by $\pm 30 \%$ from these baseline values.

The problem constraints on endogenous variables of the model are as follows:

$$
\begin{gathered}
Q V A P_{k a z}(t) \geq \overline{Q V A P}_{k a z}(t) \\
Q X A_{k a z}^{j}(t) \geq \overline{Q X A}_{k a z}^{j}(t) \\
j=1, \ldots, 16, t=2015, \ldots, 2021
\end{gathered}
$$

Here $\boldsymbol{Q V} \boldsymbol{A} \boldsymbol{P}_{\boldsymbol{k a z}}(\boldsymbol{t})$ is GDP per capita; $\overline{\boldsymbol{Q V A P}}_{\boldsymbol{k a z}}(\boldsymbol{t})$ is baseline value of GDP, $\boldsymbol{Q} \boldsymbol{X} \boldsymbol{A}_{\boldsymbol{k} \boldsymbol{a z}}^{\boldsymbol{j}}(\boldsymbol{t})$ is output of the industry $\boldsymbol{j}$ per capita, $\overline{\boldsymbol{Q X}}_{\boldsymbol{k a z}}^{j}(\boldsymbol{t})$ is baseline value of output of the industry $\boldsymbol{j}$ per capita in the Republic of Kazakhstan.

Criterion $\boldsymbol{K}$ of the problem is written as:

$$
K=\sum_{t=2015}^{2021}\left(T Q V A_{k a z}(t)+\sum_{j=1}^{N} \alpha_{k a z}^{j} T Q X A_{k a z}^{j}(t)\right)
$$

where $T Q V A_{k a z}(t)$ is growth rate of GDP per capita and $T Q X A_{k a z}^{j}(t)$ is growth rate of output of the industry $j$ per capita in the Republic of Kazakhstan in year $t$ (in current US dollars), $N=2$ is the quantity of stimulated industries, $\alpha_{k a z}^{j}$ is adjustable factor.

In this problem, the values of all uncontrollable exogenous variables of the Republic of Kazakhstan and all exogenous variables of the remaining regions correspond to the baseline forecast of the corresponding variables. The formulated problem was solved numerically using iterative optimization algorithm NLPEC [15] provided by GAMS.

The results of its solution in the form of increments of the GDP value and increments of the industries' output $j$ of the Republic of Kazakhstan by years for 2015-2021 (per capita, in percent relative to the baseline scenario) are shown in Table 2.

The results in Table 2 show that the average growth of the metal manufacture and engineering industry in 2015-2021 is $3.25 \%$, chemical and petrochemical production is $4.71 \%$ compared to the baseline forecast.

In addition, the stimulation of these industries induced growth in related industries and in industries that supply products for intermediate consumption to stimulated industries. The output of such major suppliers of intermediate products as power, gas and hot water production and transmission industry and transport industry grew by an average of $2.53 \%$. In addition, due to the increase in cash received by households, food, beverages and tobacco production output increased by an average of $5.4 \%$, manufacture of textiles, clothing, leather and related products - by an average of $5.71 \%$. The output of the financial services' sector, as the circulatory system of the economy, increased by $3.43 \%$.

From the analysis of Table 2, it can be seen that the highest growth in comparison with the baseline forecasted estimates is the manufacture of textiles, clothing, leather and related products industries and food, beverages and tobacco production industries (in average more than 5.71\%). Next are the following industries: other industries; professional, scientific and technical activities; and chemical and petrochemical production.

The average growth of $3.98 \%$ of the stimulated industries turned out to be greater than the average growth of the remaining industries of 3.55\%.

In general, as a result of the problem solving, the average GDP per capita growth for the period 2015-2021 amounted to $1.39 \%$, and the average output growth for all industries per capita amounted to $3.61 \%$ compared with the baseline version. Forecast growth of GDP per capita of 2021 with parametric control was 32.17\% from value of 2015.

Analysis of the presented results of the problem solutions and results of the corresponding test shows the high potential of the parametric control approach for developing recommendations on optimal government economic policy aimed at diversifying economic growth by stimulating selected industries. 


\section{CONCLUSION}

1. A multi-country computable general equilibrium model of interaction of functioning of world regions (the Republic of Kazakhstan, its trading partners within EAEU, big economy regions, and rest counties as one region) were developed.
2. A set of social accounting matrices (SAM) and values of elasticity coefficients were generated.

3. The possibility of transferring the results of computational experiments based on the model to the subject area was tested.

TABLE II. GROWTH COMPARED TO THE BASIC FORECAST OF OUTPUT OF INDUSTRIES AND GDP OF THE REPUBLIC OF KAZAKHSTAN AS A RESULT OF THE PROBLEM SOLUTION

\begin{tabular}{|c|c|c|c|c|c|c|c|}
\hline \multirow{2}{*}{ Industry, GDP } & \multicolumn{7}{|c|}{ Year } \\
\hline & 2015 & 2016 & 2017 & 2018 & 2019 & 2020 & 2021 \\
\hline Mining (except oil and gas) & $3.63 \%$ & $1.52 \%$ & $3.10 \%$ & $3.40 \%$ & $4.10 \%$ & $4.21 \%$ & $4.19 \%$ \\
\hline Production of crude oil and gas & $3.73 \%$ & $2.33 \%$ & $3.47 \%$ & $3.34 \%$ & $3.82 \%$ & $3.81 \%$ & $3.37 \%$ \\
\hline Metal manufacture and engineering & $2.93 \%$ & $2.58 \%$ & $3.62 \%$ & $3.55 \%$ & $3.74 \%$ & $3.57 \%$ & $2.78 \%$ \\
\hline Metallurgical industry & $3.18 \%$ & $3.70 \%$ & $4.67 \%$ & $4.61 \%$ & $4.92 \%$ & $4.38 \%$ & $3.22 \%$ \\
\hline Education, healthcare, public policy & $5.50 \%$ & $2.08 \%$ & $3.53 \%$ & $3.48 \%$ & $4.62 \%$ & $4.61 \%$ & $3.77 \%$ \\
\hline $\begin{array}{l}\text { Power, gas and hot water production and } \\
\text { transmission }\end{array}$ & $7.83 \%$ & $4.44 \%$ & $5.63 \%$ & $5.13 \%$ & $3.32 \%$ & $4.18 \%$ & $4.84 \%$ \\
\hline Food, beverages and tobacco production & $6.07 \%$ & $3.92 \%$ & $5.35 \%$ & $5.35 \%$ & $6.22 \%$ & $5.94 \%$ & $5.68 \%$ \\
\hline Professional, scientific and technical activities & $4.79 \%$ & $3.43 \%$ & $4.09 \%$ & $3.64 \%$ & $4.72 \%$ & $4.35 \%$ & $4.64 \%$ \\
\hline Other industries & $4.64 \%$ & $2.37 \%$ & $4.89 \%$ & $4.82 \%$ & $5.33 \%$ & $4.93 \%$ & $4.19 \%$ \\
\hline Other services & $3.27 \%$ & $1.06 \%$ & $2.82 \%$ & $3.21 \%$ & $3.87 \%$ & $3.75 \%$ & $4.05 \%$ \\
\hline Farming, forestry and fishing & $1.36 \%$ & $1.19 \%$ & $2.21 \%$ & $2.32 \%$ & $3.32 \%$ & $3.25 \%$ & $2.40 \%$ \\
\hline Construction & $0.49 \%$ & $0.19 \%$ & $1.04 \%$ & $1.23 \%$ & $1.58 \%$ & $1.57 \%$ & $0.92 \%$ \\
\hline $\begin{array}{l}\text { Manufacture of textiles, clothing, leather and related } \\
\text { products }\end{array}$ & $7.17 \%$ & $3.10 \%$ & $5.91 \%$ & $5.39 \%$ & $6.14 \%$ & $6.30 \%$ & $5.94 \%$ \\
\hline Financial services & $4.29 \%$ & $2.72 \%$ & $2.77 \%$ & $2.77 \%$ & $3.97 \%$ & $4.05 \%$ & $3.57 \%$ \\
\hline Chemical and petrochemical production & $5.50 \%$ & $2.57 \%$ & $4.44 \%$ & $4.37 \%$ & $5.67 \%$ & $5.46 \%$ & $4.94 \%$ \\
\hline Transport & $2.07 \%$ & $2.27 \%$ & $1.75 \%$ & $1.61 \%$ & $1.51 \%$ & $1.39 \%$ & $2.16 \%$ \\
\hline GDP & $1.44 \%$ & $1.28 \%$ & $1.24 \%$ & $1.25 \%$ & $1.53 \%$ & $1.56 \%$ & $1.42 \%$ \\
\hline
\end{tabular}

4. The effectiveness of economic growth diversification by stimulating certain economic sectors was shown through formulating and solving the problem of parametric growth on the example of the Republic of Kazakhstan.

\section{REFERENCES}

[1] Z. Kristkova, "Impact of R\&D investments on the economic growth of the CzechRepublic - a recursively dynamic CGE approach,” Prague Economic Papers, no. 4, 2012.

[2] A. Pallegedara, "Impacts of Service Sector Policy Reforms:CGE Model Analysis Based on Sri Lanka,” Wayamba Journal of Management, no. 3 (2), 2014.

[3] M. Ciaschini, R. Pretaroli, F. Severini and C. Socci, "Health Care Services and Economic Impact: a Dynamic CGE Approach,” Universita degli Studi di Macerata, Quaderno di Dipartimento, no. 74, 2014.

[4] C. Hannuma, H. Cutlerb, T. Iversonb and D. Keyserc, "Estimating the implied cost of carbon in future scenarios using a CGE model: The Case of Colorado,” Energy Policy, vol. 102, 2017, pp. 500-511.

[5] D.M. Radulescu, CGE Models and Capital Income Tax Reforms: The Case of a Dual Income Tax for Germany, Springer 2007.
[6] A. Estache, J. Perrault and L. Savard, "The Impact of Infrastructure Spending in Sub-Saharan Africa: A CGE Modeling Approach,” Hindawi Publishing Corporation, Economics Research International, vol. 2012, 2012.

[7] The General Algebraic Modeling System (GAMS), http://www.gams.com/.

[8] GTAP Data Base, http://www.gtap.agecon.purdue.edu/.

[9] GLOBE CGE Model, www.cgemod.org.uk/.

[10] Handbook of Input-Output Table Compilation and Analysis, United Nations, 1999.

[11] World Input-Output Database, http://www.wiod.org/.

[12] I. Fofana, A. Lemelin and J. Cockburn, "Balancing a Social Accounting Matrix: Theory and Application,” Partnership for Economic Policy, 2013.

[13] World Economic Outlook Databases, http://www.imf.org/.

[14] A. Ashimov, Zh. Adilov, R. Alshanov, Yu. Borovskiy and B.Sultanov, "The Theory of Parametric Control of Macroeconomic Systems and Its Applications,” Advances in Systems Science and Application, vol.14, no.1, pp. 1-21, 2014.

[15] M. Ferris and T. Munson, “PATH 4.7.,” GAMS Development Corporation, 2016. 